\title{
ESPECTÁCULOS Y TEXTOS TEATRALES EN CASTILLA A FINES DE LA EDAD MEDIA
}

\author{
Miguel Ảngel Pérez Priego
}

$U N E D$

La casi absoluta inexistencia de textos dramáticos desde el Auto de los Reyes Magos (fines del siglo XII) a las piezas de Gómez Manrique (hacia 1470), ha ocasionado que la historia del teatro medieval castellano se nos aparezca envuelta en una bruma de perplejidades que lo han convertido en uno de los capítulos más oscuros y debatidos de toda nuestra historia literaria. Por fortuna, ese nebuloso panorama - aun sin desvelar del todo sus sombras - comienza a despejarse a medida que nos adentramos en el siglo XV, época crucial para tantos aspectos de la historia y la cultura españolas. De ese período, en efecto, poseemos ya algunas noticias documentales sobre actividades dramáticas $\mathrm{y}$, sobre todo, un cierto corpus de textos literarios indisputablemente dramáticos (sin hacer cuenta de otros quizá más discutibles). Podemos considerar, pues, nutrida la documentación teatral existente, que además no deja de verse incrementada por las aportaciones de la investigación a lo largo de los últimos años. Quizá, por ello, sea hora de establecer un balance y de tratar de ordenar en el discurso crítico los datos, noticias y obras con las que en el momento presente contamos. Tal es el propósito de las páginas que siguen.

Dos focos principales de producción dramática se detectan en el período cuatrocentista: por un lado, la Iglesia, en torno a sus sedes catedralicias, sus templos parroquiales o sus conventos y monasterios; y por otro, la Corte, en torno a los palacios señoriales o la propia corte regia. Del teatro eclesiástico nos han transmitido informaciones valiosas algunas actas conciliares y constituciones sinodales de la época ${ }^{1}$. Las más elocuentes son tal

' Si es cierto que este tipo de testimonios debe tomarse siempre con cautela por cuanto tales disposiciones suelen repetir ecos de la vieja condena del teatro por parte de los moralistas 
vez las famosás del concilio de Aranda, convocado en 1473 por Alonso Carrillo con carácter provincial para todo su arzobispado de Toledo. Según esas actas indican en su canon XIX, existía costumbre en las iglesias de la provincia, con motivo de determinadas festividades (Navidad, San Esteban, San Juan, los Inocentes, otros dias festivos y misas nuevas), de ejecutar durante los oficios diversa suerte de juegos escénicos, espectáculos y ficciones 'inhonestas':

Quae vero quaedam tam in metropolitanis quam in cathedralibus et aliis ecclesiis nostrae provinciae consuetudo inolevit ut videlicet in festis Nativitatis Domini Nostri Jesuchristi, et sanctorum Stephani, Joannis et Innocentuum. aliisque certis diebus festivis, etiam in solemnitatibus missarum novarum, dum divina aguntur, ludi theatrales, larvae, monstra, spectacula, necnon quamplurima inhonesta et diversa figmenta in ecclesiis introducuntur; tumultuationes quoque et turpia carmina et desisorii sermones dicuntur, adeo quod divinum officium impediunt et populum reddunt indevotum.

Tales juegos y espectáculos, sobre cuyas exactas dimensiones y condición no caben sino conjeturas, son prohibidos por el concilio y, en cambio, son permitidas y alentadas para esos mismos días las representaciones honestas y piadosas que muevan al pueblo a devoción:

Nos hanc corruptelam, sacro approbante concilio, revocantes hujusmodi larvas, ludos, monstra, spectacula, figmenta, tumultuationes fieri, carmina quoque turpia, et sermones illicitos dici, tam in metropolitanis quam in cathedralibus ceterisque nostrae provinciae ecclesiis, dum divina celebrantur, praesentium serie omnino prohibemus (...) Per hoc tamen honestas repraesentationes

romanos y de los padres de la Iglesia, no es menos cierto, como ha observado J. E. Varey ( $A$ Note on the Councils of the Church and Early Dramatic Spectacles in Spain», en Medieval Hispanic Studies presented to Rita Hamilton, Londres, Tamesis Books, 1976, pp. 241-44) que a lo largo del tiempo se produjeron diversos impulsos reformadores, como el del obispo Paciano en el siglo IV, el de Inocencio IIl y el concilio de Letrán o el de la implantación de la fiesta y procesión del Corpus, que fueron modificando la actitud de la Iglesia ante el espectáculo teatral, actitud que inevitablemente pasarian a reflejar los cánones y decretos oficiales. Nuestros textos del siglo $\mathrm{xv}$, en los que ciertamente no dejan de resonar ecos de la antigua condena y controversia, contienen sin embargo buen número de referencias concretas y coloristas que permiten interpretarlos como reflejo bastante aproximado de la realidad de su tiempo. 
et devotas, quae populum ad devotionem movent, tam in praefatis diebus quam in aliis non intendimus prohibere?

En términos semejantes se expresan las actas del concilio Complutense celebrado en Alcalá en 1480, las constituciones sinodales de Ávila dictadas por el obispo Alonso de Fonseca en 1481 o, ya cerrado el siglo, en 1501, las del obispo Alonso Manrique para su diócesis de Badajoz $z^{3}$.

En sustancia, de lo que todos esos testimonios nos hablan es de un teatro que tradicionalmente viene representándose en las iglesias con motivo de determinadas festividades, fundamentalmente la Navidad como ya indica el concilio de Aranda (pero bien entendido que incluyendo en ella todo un ciclo que comprende también las festividades de San Esteban, San Juan y los Inocentes, esto es, los días segundo, tercero y cuarto de pascua, correspondientes al 26, 27 y 28 de diciembre) ${ }^{4}$, y también la Pasión y Resurrección

2 Juan Tejada y Ramiro, Colección de cánones y de todos los concilios de la Iglesia de España $y$ de América. V, Madrid, 1855, pp. 24-25. Recientemente F. Mendoza Díaz-Maroto, «El Concilio de Aranda (1473) y el teatro medieval castellano", Criticón, 26 (1984), 5-15, ha dado a conocer una traducción contemporánea de este famoso fragmento, conservada en un documento del archivo de la catedral de Toledo y destinada seguramente a la difusión en las parroquias de las disposiciones del concilio. Conviene notar que en esa versión abreviada en castellano se utilizó ya el término representaciones como equivalente de los ludi, larvae, monstra, spectacula, figmenta del texto latino: «(...) quiere en efecto que, en tanto que se faze el ofiçio divino, no se fagan en las iglesias ni en las solenidades de las misas nuevas juegos ni representaçiones desonestas ni se digan sermones iliçitos (...) Pero por esto no se defienden las representaçiones devotas e onestas que mueven al pueblo a devoçión».

"Las disposiciones del concilio Complutense son citadas por J. Amador de los Ríos en su Historia critica de la literatura española. VII, Madrid, 1865, p. 472, n. El fragmento correspondiente de las sinodales de Ávila ha sido transcrito últimamente por A. Gómez Moreno, "Teatro religioso medieval en Ávila", El Crotalón, 1 (1984), 769-775. Las de Badajoz fueron ya recogidas por A. Rodriguez-Moñino, "Historia literaria de Extremadura. La Edad Media y los Reyes Católicos", $R E E, 6(1950)$, pp. 114-15, y ahora por Ana M." Álvarez Pellitero, "Aportaciones al estudio del teatro medieval en España», El Crotalón. 2 (1985), 13-35. Junto a otras disposiciones eclesiásticas del mismo género, me refiero a las de Badajoz y a las de Ávila en mi estudio El teatro de Diego Sánchez de Badajoz, Cáceres, Universidad de Extremadura, 1982, pp. $42-44$.

${ }^{4}$ Cfr. este significativo pasaje de la Crónica del Condestable Miguel Lucas de Iranzo, ed. Juan de Mata Carriazo, Madrid, 1940, p. 156: «E] segundo día de pascua [de Navidad], que es la fiesta de San Estevan, y el terçero y quarto, que son días de Sant Juan apóstol y evangelista e de los Ynoçentes (...)». Las representaciones de esos días, por consiguiente, debian ser de asunto relacionado con la Navidad. No creo que haya que pensar, como a veces se ha hecho, en escenificaciones de "vidas de santos» (la alusión de las constituciones de Ávila parece muy genérica y ya fuera de contexto: "pero por esto non quitamos ni defendemos que non se faga... la representación de algún sancto o fiesta dél») y mucho menos confundir esta fiesta de San Juan con la de San Juan Bautista del solsticio de verano, y sostener que los bailes y mascaradas con que ésta sería celebrada eran condenados por nuestro texto del concilio de Aranda (así, por ejemplo, J. Caro Baroja, La estación de amor (fiestas populares de mavo a San Juan). Madrid, Taurus, 1979, p. 260). 
como explicitan las constituciones de Badajoz ( fazen representaciones de los misterios de la Natividad e de la Pasión e Resurrección de Nuestro Señor...»). Ese teatro, sin embargo, venía produciéndose con cierta perturbación del culto, ya que ocurría durante el oficio divino, y, sobre todo, con inhonestidades y peligrosos desvíos de la auténtica devoción de los fieles. No sabemos bien en qué consistían estas 'inhonestidades', pero, conforme denuncian las constituciones de Ávila, parece que residían en la propia intervención de los clérigos, que «salen y acostumbran fazer çaharrones y vestir hábitos contrarios a su profesión, trayendo vestiduras de mugeres y de frailes y de otros diversos hábitos, y pónense otras caras de las que Nuestro Señor les quiso dar, faziéndose homarraches, e dizen muchas burlas e escarnios e cosas torpes e feas e deshonestas"; o, como condenan las de Badajoz, consistirían en «las palabras deshonestas y de gran disolución» que acompañaban a las representaciones, asi como en los "cacephatones e cantares torpes e feos" que se usaban decir la noche de Navidad. Tales excesos serán la causa de que algunos prelados, como Alonso Manrique, determinen prohibir todo tipo de espectáculos en los templos («ordenamos e mandamos que las tales representaciones de aquí adelante no se fagan... E si algunas cosas quisieren cantar en tanto que las leciones se dizen, que sean cantares devotos, adaptados al misterio e solenidad de la fiesta»), o de que otros, como Carrillo y Fonseca, traten de eliminarlos fomentando, en cambio, las representaciones más devotas y piadosas ( Pero por esto non quitamos nin defendemos que non se faga el obispillo e las cosas e actos a él pertenescientes onesta e devotamente que por ciertos misterios se suelen acostumbrar fazer cada año; asimismo la representación de algún sancto o fiesta dél»). En cualquier caso, lo que todas estas disposiciones vienen a testimoniar es la existencia de una viva actividad teatral en las iglesias, que goza de la aceptación de los fieles y hasta ha podido llegar a convertirse en un hecho más de la vida diaria. Como cuenta Alfonso Martínez de Toledo en su Arcipreste de Talavera o Corbacho (1438), la representación en el templo es incluso ocasión propicia que aprovecha la mujer vanagloriosa para ser vista y mirada:

Dice la fija a la madre, la muger al marido, la hermana a su hermano, la prima a su primo, la amiga a su amigo: «Ay, cómo estó enojada! Duéleme la cabeça; siéntome de todo el cuerpo; el estómago tengo destemprado estando entre estas paredes. Quiero ir a los perdones; quiero ir a Sant Francisco; quiero ir a misa a Santo Domingo; representaçión fazen de la Pasión al Carmen (...)»\$.

' Alfonso Martínez de Toledo, Arcipreste de Talavera o Corbacho, 2." parte, cap. IX, ed. Michael Gerli, Madrid, Cátedra, 1979, pp. 184-85. Cita ya este ilustrativo pasaje J. Amador de los Ríos, Historia critica..., cit., VII, p. 472 , n. 1. 
Será precisamente Toledo —donde ejerció también su cargo Alfonso Martínez y fue mantenedor de las fiestas religiosas entre 1450 y 1460 - el centro que mejor documentada tenga esta actividad dramática reseñada. En Toledo, destacado foco teatral peninsular desde el siglo XIII, la investigación de los últimos años ha descubierto, en efecto, una muy vigorosa presencia de espectáculos teatrales, de los que dan cuenta las noticias indirectas de los libros de gasto y fábrica de la catedral ${ }^{6}$. A partir de esas noticias sabemos que había representaciones dramáticas con motivo de las fiestas de Navidad, Pasión y, sobre todo, del Corpus Christi, que aquí se celebraba con gran esplendor y espectacularidad: de 1493 a 1510 se documentan nada menos que treinta y tres autos diferentes que fueron representados en la procesión del Corpus a lo largo de aquel tiempo. De ellos conocemos su título y algunas noticias acerca de su representación, la cual hubo de alcanzar en ocasiones gran desarrollo escenográfico. Sin embargo, no nos ha llegado texto literario alguno y cabe pensar que éste debía de ser bastante elemental y reducido, quizá simplemente las «coplas e dichos» de que hablan los documentos, coplas que estarian tomadas de otros textos literarios de diversa procedencia o pedidas de encargo a algunas personas relacionadas con la vida de la catedral.

El único texto toledano completo que se conserva, y que ha venido a enriquecer el panorama teatral cuatrocentista, es el Auto de la Pasión de Alonso del Campo, capellán de coro de la catedral y organizador de las fiestas, quien hubo de escribirlo entre 1486 y 1499 , fecha ésta de su muerte. El auto, conservado en las páginas que habían quedado en blanco de un libro de cuentas del archivo de fábrica de la catedral, es una recreación escénica de algunos episodios evangélicos de la pasión de Cristo: la oración en el huerto, la traición de Judas y el prendimiento del Maestro, las negaciones de Pedro, la sentencia de Pilatos, y el encuentro de San Juan y la Virgen. Con esas escenas alternan tres monólogos o plantos sucesivos a cargo respectivamente de San Pedro (vv. 221-310), San Juan (vv. 311-415) y la Virgen (vv. 542-599), en los que, junto a las lamentaciones patéticas y doloridas, se evocan, desde el sentimiento personal, aquellas mismas escenas así como otros episodios de la Pasión no escenificados en la obra. Hay así en el auto un curioso juego de perspectivas, en el que se combina la acción histórica directamente representada con la evocación lírica e indirecta a cargo de protagonistas y testigos presenciales de los hechos. Todo ello presta a la obra un tono de piadoso recogimiento y devoción sentida, muy acorde con la ocasión y el asunto representado, y en línea con aquellas disposiciones regeneradoras de los concilios, ya comentadas. Por lo demás, conviene ad-

- Para todo lo referente a este teatro toledano, véase el estudio de Carmen Torroja Menéndez y María Rivas Palá, Teatro en Toledo en el siglo XV. "Auto de la Pasión» de Alonso del Campo, Madrid, Real Academia Española, 1977. 
vertir que la materia argumental está mayoritariamente tomada de los evangelios canónicos, aunque algún episodio, como el de la sentencia de Pilatos, procede de los apócrifos, y alrededor de una cuarta parte del texto no hace sino reproducir versos de la Pasión trovada de Diego de San Pedro?.

Si el auto de Alonso del Campo viene a documentarnos cómo eran las representaciones castellanas del ciclo de Pasión a fines del siglo XV, la obra de Gómez Manrique, quien también trata esquemáticamente el mismo asunto en sus Lamentaciones fechas para la Semana Santa, nos da testimonio además del otro gran ciclo del drama sacro medieval, el de la Navidad. Para tal ocasión, en efecto, escribió nuestro poeta, entre 1458 y 1481 (quizá hacia 1476), una Representaçión del Nasçimiento de Nuestro Señor, que es la muestra más significativa del teatro religioso anterior a Juan del Encina ${ }^{8}$. No sabemos a ciencia cierta cómo fue en Castilla el desarrollo de este teatro navideño, al que una y otra vez aluden las disposiciones conciliares anteriormente comentadas. Por las muestras dispersas que se han conservado hasta mediados del siglo XVI, parece que se desarrolló tanto una tradición vulgarizadora del drama litúrgico - del Officium pastorum - como, sobre todo, una tradición vernácula formada a partir del relato evangélico en que San Lucas narra el nacimiento de Cristo. Lo que prosperó, en definitiva, fue un modelo representacional que ponia en escena los tres cuadros principales de aquel relato: el anuncio del ángel a los pastores, la marcha de éstos al nacimiento, y la adoración y ofrenda de presentes. Sobre ese esquema, gracias sin duda al ejemplo modélico de Fray lñigo de Mendoza y sus Coplas de Vita Christi, se desarrollaría aún un episodio de enorme éxito y popularidad: el coloquio de los pastores en una lengua rústica y artificiosa -el llamado sayagués-, que será ya durante siglos rasgo caracterizador esencial del pastor de teatro y que introduce un elemento cómico en la

' El auto de Alonso del Campo ha sido estudiado y editado por C. Torroja y M." Rivas en el trabajo anteriormente citado, pp. 77-141 y 157-180. Lo incluye también Ronald E. Surtz en su edición de Teatro medieval castellano, Madrid, Taurus, 1983, pp. 71-91. En un último e inteligente trabajo, Alberto Blecua, "Sobre la autoría del Auto de la Pasión", en Homenaje a Eugenio Asensio, Madrid, Gredos, 1988, pp. 79-112, defiende con razones de peso el carácter arcaico y fragmentario de la obra y rechaza, en consecuencia, la originalidad de Alonso del Campo, quien realizaría sólo una labor de taracea y de adaptación.

${ }^{8}$ Una cuidada fijación crítica del texto ha llevado a cabo F. López. Estrada, "La representación del Nacimiento de Nuestro Señor, de Gómez Manrique: estudio textual», Segismundo, 39-40 (1984), 9-30. La pieza ha sido estudiada literariamente por Harry Sieber, "Dramatic Symmetry in Gómez Manrique's La representación del Nacimiento de Nuestro Señor», $H R, 33$ (1965), 118-35; Stanislav Zimic, "El teatro religioso de Gómez Manrique (1412-1491)», BRAE, 57 (1977), 353-400; y F. López Estrada, «Nueva lectura de la Representación del Nacimiento de Nuestro Señor, de Gómez Manrique", en Atti del IV Colloquio della Societé Internationale pour l'Étude du Théatre Médiéval, Viterbo, Centro di Studi sul Teatro Medioevale e Rinascimentale, 1984, pp. 423-46. 
representación sacra, muy eficaz también, dentro del estilo jocoserio, para sus propósitos didácticos?.

La pieza de Manrique no explota todavía este coloquio cómico-pastoril, pero sí aprovecha el modelo tripartito del anuncio, la marcha hacia el pesebre y la adoración. Ese esquema convencional, sin embargo, es notablemente amplificado por nuestro dramaturgo mediante la inserción original de otros episodios de gran rendimiento dramático. Al comienzo de la obra, por ejemplo, añadirá una curiosa escena en la que José expresa sus dudas y sospechas por la concepción de María ( ${ }_{i} \mathrm{O}$ viejo desventurado! / Negra dicha fue la mía / en casarme con María / por quien fuesse deshonrado. / Yo la veo bien preñada, / no sé de quién ni de cuánto. / Dizen que d'Espíritu Santo, / mas yo desto no sé nada"), dudas que en seguida le disiparán la propia Virgen y el Ángel. Otra novedad semejante presenta el final de la pieza, donde, tras la adoración de los pastores y los ángeles, se inserta el episodio original de la ofrenda de los instrumentos simbólicos de la Pasión (el cáliz, la soga, los azotes, la corona de espinas, los clavos y la lanza). De este modo, si aquella primera escena suponía un feliz arranque teatral de la obra e introducia una cierta comicidad realista, la segunda sugiere una patética asociación del nacimiento de Cristo con la Pasión y con la Redención, motivo temático, como bien ha visto R. E. Surtz, muy característico de las formas de devoción franciscana ${ }^{10}$. A ese propósito, es muy significativo que la obra fuera escrita por Gómez Manrique a instancias de su hermana doña María Manrique, vicaria del monasterio franciscano de $\mathrm{Ca}$ labazanos, y fuera representada por las propias monjas del convento, según se infiere de alguna de las rúbricas del texto ( $\angle a$ que representa a la Gloriosa, cuando le dieren el Niño») y, sobre todo, de la emotiva "Canción para callar el Niño" que, en metro zejelesco y como contrapunto de la rica polimetria de toda la obra, pone fin a ésta:

Callad, fijo mio chiquito.

Calladvos, Señor, nuestro Redentor, que vuestro dolor durará poquito.

Ángeles del cielo, venid dar consuelo a este moçuelo

\footnotetext{
9 Sobre esta evolución del drama de Navidad en el primitivo teatro español, véase M. A. Pérez Priego, El teatro de Diego Sánchez de Badajoz, cit., pp. 97-107.

"Ronald E. Surtz, "The 'Franciscan connection' in the early castilian theater", Bulletin of the Comediantes, 35, 2 (1983), pp. 141-52.
} 
Jesús tan bonito (...)

Cantemos gozosas, ermanas graciosas, pues somos esposas del Jesús bendito.

Al mismo ambiente conventual y devoción franciscanas responde el anónimo Auto de la huida a Egipto, también de finales de siglo (entre 1446 y 1512 , como fechas extremas) y escrito para el convento de clarisas de Santa María de la Bretonera, en la provincia de Burgos. La obra, descubierta y dada a conocer en $1948^{\prime \prime}$, es también una de aquellas representaciones que se harían para la fiesta de Navidad - probablemente, por su argumento, para el día de los Inocentes-, pero basada en todo caso en una tradición vernácula ya alejada de los argumentos del puro drama litúrgico. El auto pone en escena, en efecto, otro episodio de la infancia de Cristo, en este caso el de la huida de la Sagrada Familia desde Judea a Egipto ante la amenaza de Herodes. Para eso sigue el relato evangélico de San Mateo $(2,13-$ 21), si bien le añade el breve episodio amplificativo, tomado de los apócrifos, del encuentro con los tres ladrones que, tras robarles, se arrepienten y se postran ante ellos (el más joven será todavía el que se convierta junto a Cristo en la cruz). A esa primera acción de la huida y el encuentro con los ladrones se yuxtapone además una segunda protagonizada por Juan el Bautista, retirado al desierto y a la espera del Mesías, también conforme al relato de San Mateo (3,1-4). Este segundo episodio se ve igualmente amplificado con la presencia de un nuevo personaje, original en la trama del auto: el Peregrino que viene de Egipto y a quien Juan hace retornar allí para adorar a la Sagrada Familia y traerle nuevas del Mesías nacido, y que terminará además convertido a la vida ascética y eremítica:

\footnotetext{
Sabe, Juan, que soy mudado, que no soy quien ser solia. Cuando vine en romería, de tu vida fue espantado.

Ora sé que Dios es vida y la su graçia es hartura. Quedemos en la espsura esperando su venida (...)
}

"Auto de la huida a Egipto, edición de Justo García Morales, Madrid, Joyas Bibliográficas de la Biblioteca Nacional, II, 1948. Ha sido también editado y estudiado por José Amícola, «El Auto de la huida a Egipto, drama anónimo del siglo XV", Filologia, 15 (1971), pp. 1-29. Asimismo lo recoge R. E. Surtz, Teatro medieval castellano, cit., pp. 92-109. 
Para mejor dotrinarme,

Juan, de las yervas comamos,

$y$, pues el mundo dexamos,

no quiero engolosinarme.

Era amigo de dulçores.

Mira, Juan, lo que te digo.

Después que topé contigo,

sólo en Dios hallo favores.

Si argumentalmente, como se advierte, el auto presenta una notable complejidad, artísticamente resulta también muy elaborado. Para su puesta en escena se requeriría todo el artificio de un escenario múltiple y simultáneo, repartido en diversas mansiones donde se desarrollara la acción: la casa en Judea, el paraje hosco de camino donde la Sagrada Familia es asaltada por los ladrones, la estancia en Egipto y el desierto donde hace penitencia Juan. De unas a otras se irian trasladando sucesivamente los personajes, momento que suele marcar la tonada de un villancico o una canción («Oyendo Josepe al ángel, va cantando este villançico», «Buélvese el Peregrino a Egipto cantando", etc.). Un gran acierto compositivo, en fin, es el personaje del Peregrino que si, por un lado, cumple la función de unị hábilmente los dos episodios argumentales del auto, por otro, sirve de enlace con el espectador, a quien de forma inmediata transmitiría toda la emotividad de su conversión piadosa. Ese efecto catártico, conseguido a través de estos personajes puente con el espectador -el Peregrino y también los ladrones-, que experimentan en sí mismos la eficacia doctrinal de la obra, resulta un feliz hallazgo teatral y una admirable respuesta a aquellos propósitos de mover a devoción que buscaba el teatro de la época.

El otro foco principal de producción teatral en el período cuatrocentista es la corte, los palacios del rey y de la nobleza. Hay, como es sabido, en estas cortes principescas del otoño de la Edad Media una fuerte tendencia a la teatralización de casi todos los sucesos de la vida diaria. Con motivo de los más distintos acontecimientos y ocasiones se organizan desfiles, danzas, juegos, torneos y espectáculos diversos, en los que se concede especial importancia al artificio visual, a la música o al vestuario. Incluso parte de la actividad literaria cobra un cierto grado de teatralidad, y así ocurre con la ejecución de numerosos género poéticos, como, por ejemplo, las serranillas, las preguntas y respuestas, las letras e invenciones, y muchos de los poemas dialogados de los cancioneros.

No es, pues, extraño que la corte incorporara en seguida a su ámbito las representaciones dramáticas de las iglesias y convirtiera esa práctica tea- 
tral en espectáculo cortesano. La Crónica del condestable Miguel Lucas de Iranzo, magnífico y revelador documento sobre la vida en una corte castellana fronteriza en la época de Enrique IV, nos da cuenta, por ejemplo, de cómo el citado condestable de Castilla, todos los años para las fiestas de Navidad, en las salas de su palacio jienense, hacia representar $-\mathrm{y}$ hasta intervenía él mismo en la representación- dos espectáculos dramáticos distintos, la Estoria del Nascimiento del Nuestro Señor e Salvador Jesucristo y de los pastores y la Estoria de quando los Reyes vinieron a adorar y dar sus presentes a Nuestro Señor Jesucristo. De esta última incluso nos ha dejado una preciosa descripción de su representación en el año 1462:

\begin{abstract}
Y desque ovieron çenado y levantaron las mesas, entró por la sala una dueña, cavallera en un asnico sardesco, con un niño en los braços, que representava ser nuestra señora la Virgen Maria con el su bendito e glorioso Fijo, e con ella Josep. Y en modo de grant devoçión, el dicho señor Condestable la reçibió, e la subió arriba al asiento do estava, y la puso entre la dicha señora condesa e la señora doña Guiomar Carrillo su madre e la señora doña Juana su hermana, e las otras dueñas e doncellas que ende estavan. Y el dicho señor se retrayó a una cámara con dos pajes muy bien vestidos, con visajes e sus coronas e las cabeças, a la manera de los tres Reyes Magos, y sendas copas en las manos, con sus presentes. $Y$ asi movió por la sala adelante, muy mucho paso, e con muy gentil contenençia, mirando el estrella que los guiava, la qual iva por un cordel que en la dicha sala estava. E así llegó al cabo della, do la Virgen con su Fijo estavan, e ofresció sus presentes, con muy grant estruendo de tronpetas e atabales y otros estormentos ${ }^{12}$.
\end{abstract}

Ambas representaciones, como ya por su título y por esta descripción se advierte, diferirian muy poco de las que se ejecutaban en las iglesias en la tradición del Officium pastorum y del Ordo stellae del drama litúrgico. La gran novedad consiste en haber sustituido las naves del templo por las salas de palacio, así como a los clérigos y cantores por los nobles y pajes cortesanos. Por lo demás, conforme se desprende de la descripción, la presencia de unos «actores" que encarnan distintos papeles, el movimiento escénico a lo largo de la sala y el aparato escenográfico de vestidos, visajes, accesorios y músicas, son ya marcas inequivocas de la teatralidad del espectáculo.

${ }^{12}$ Hechos del Condestable don Miguel Luchas de Iranzo, ed. cit., pp. 71-72. La importancia de la crónica para los origenes del teatro castellano fue ya advertida por Ch. V. Aubrun, "La chronique de Miguel Lucas de Iranzo", BHi, 44 (1942), 81-95. Sobre la variedad de fiestas en ella descritas, véase ahora Lucien Clare, «Fêtes, jeux et divertissements à la cour du Connetable de Castille Miguel Lucas de Iranzo (1460-1470). Les exercices physiques", en La fête et l'ecriture. Théâtre de Cour, Cour-Théâtre en Espagne et en Italie, 1450-1530, Aix-en-Provence, Université de Provence, 1987, pp. 5-32. 
No obstante, el espectáculo teatral $\longrightarrow 0$ si se quiere, parateatral- más representativo que se produce en la corte es el del momo, al que aluden reiteradamente las crónicas de la época, si bien de forma un tanto genérica y sin entrar apenas en detalles descriptivos, por lo que tampoco resulta fácil definirlo en su exacta condición y significado ${ }^{13}$. Por lo que podemos deducir de los textos, el momo era un espectáculo diverso, y con el nombre se aludía tanto a las personas que en él intervenían como al mismo espectáculo y representación. Se trataba de un espectáculo propio de la corte - se documenta tanto en la castellana como en la portuguesa-, en el que solían intervenir todos los personajes cortesanos, desde el rey al último paje, y, hacia mediados del siglo Xv, era nuevo en Castilla, según el conocido testimonio de Alonso de Cartagena:

\begin{abstract}
El juego que nuevamente agora se usa de los momos, aunque de dentro dél esté onestat e maduretat e gravedat entera, pero escandalizase quien ve fijosdalgo de estado con visajes ageneos. E creo que non lo usarian si supiesen de quál vocablo latino desciende esta palabra $\mathrm{momo}^{14}$.
\end{abstract}

Como ha hecho notar Eugenio Asensio, a partir de las referencias de las crónicas, que los describen siempre en una determinada secuencia, los momos se insertaban en un espectáculo cortesano más amplio: primero, durante el día, se habian celebrado los torneos y justas; y luego, por la noche, después de la cena y en la misma sala del palacio, tenían lugar los momos, llegaba la hora del momear, que concluía con bailes y danzas. De ese modo, quedaba todo enmarcado en el común ritual cortesano y se producía una sugerente asociación y continuidad entre la justa y el momo, la lucha y la

${ }^{13}$ Muy próximo al momo, si no idéntico, debia de ser entonces en Castilla el espectáculo al que también se refieren las crónicas con el término entremés, tomado seguramente del catalán y con el que igualmente designaban una diversión o entretenimiento cortesano en el que intervenían máscaras, músicas y danzas (vid. E. Cotarelo y Mori, Colección de entremeses, loas, bailes, jácaras y mojiganzas desde fines del siglo XVI a mediados del XVIII, Madrid, NBAE, I, 1911, pp. LIV-LVII; W. S. Jack, The early 'entremés' in Spain: the rise of a dramatic form, Filadelfia, 1923, pp. 9-19; F. Lázaro Carreter, «El Arte nuevo (vs. 64-73) y el término entremés», $A L M, 5,1965$, pp. 77-92).

i4 Glosa de Alonso de Cartagena al cap. XIII del lib. $2{ }^{\circ}$ del Libro de la Providencia divinal de Séneca, citado por primera vez por J. Amador de los Ríos, Historia critica..., VII, p. 470, n. En ese mismo lugar recuerda Amador otro significativo pasaje de Cartagena en su Doctrinal de caballeros: "Dos cosas son en que sin actos de guerra al tiempo de hoy los fijosdalgo usan las armas... la una es en contiendas del reino; la otra es en juegos de armas, así como los torneos e justas, e estos autos, que agora nuevamente aprendimos, que llaman entremeses». A ellos alude también Juan de Mena en las Coplas de los pecados mortales, vv. 429-430: «Del ipócrita diría/ser momo de falsa cara...». 
mascarada, teñida ésta de cierto erotismo, pues a ella ponía fin el baile con la dama que era el premio a los justadores y galanes ${ }^{15}$.

Elemento esencial del momo, junto a la música y la danza, era el atuendo, las máscaras y visajes con que aparecían revestidas las personas que los interpretaban. También muchas veces poseían texto y letra: cartas, canciones, tiradas de versos que recitaban los personajes que allí intervenian. De Gómez Manrique conocemos, en efecto, unos que compuso «En nombre de las Virtudes que ivan momos al nascimiento de un sobrino suyo", donde aparecen las siete Virtudes que sucesivamente recitan una estrofa de parabienes y felicitación al recién nacido; y otros, por encargo de la infanta doña Isabel en honor del príncipe don Alfonso con motivo de su mayoría de edad, en 1467 , en los que intervienen nueve damas que representan a las nueve musas, cada una de las cuales recita un texto, un "fado», con un pronóstico de buenaventura para el príncipe ${ }^{16}$.

Asunto muy frecuente, como muestran los momos de Gómez Manrique, era éste del homenaje y exaltación encomiástica de un personaje principal de la vida de la corte, con motivo de su nacimiento, su mayoría de edad, sus bodas, etc. De ese género son también los que tuvieron lugar en 1435 con ocasión del nacimiento de un hijo al condestable don Álvaro de Luna, que refiere la Crónica del Halconero ${ }^{17}$; o los que hizo el conde de Haro en Briviesca, el año 1440, en el suntuoso recibimiento a la princesa doña Blanca de Navarra que venía a casar con el príncipe don Enrique de Castilla, de los que da cuenta la Crónica de Juan $I^{18}$. Con más detalle conocemos los

15 Eugenio Asensio, «De los momos cortesanos a los autos caballerescos de Gil Vicente», recogido en sus Estudios portugueses, Paris, Fundação Calouste Gulbenkian, 1974, pp. 25-36.

${ }_{16}$ Los dos textos de Gómez Manrique pueden verse en R. Foulché-Delbosc, Cancionero castellano del siglo XV, II, Madrid, NBAE, 1915, pp. 9-10 y 101,102.

${ }_{17}$ Vid. Pedro Carrillo de Huete, Crónica del Halconero de Juan II, ed. Juan de Mata Carriazo, Madrid, 1946, p. 212; y Lope Barrientos, Refundición de la Crónica del Halconero, ed. J. de M. Carriazo, Madrid, 1946, p. 186 ( $\ll$ E después que mucho ovieron dançado, e fecho momos, retraxéronse a esta sala muy bien arreada, de muchos tapizes e brocados...,). Otros momos mencionados en estas crónicas son los celebrados en Valladolid el primero de mayo de 1434 en la fiesta de recibimiento que ofreció don Álvaro de Luna al Rey, o los que tuvieron lugar en Soria en 1435 con motivo del recibimiento que hizo Juan II a su hermana doña María de Aragón.

${ }_{18}$ "Y en los tres días siempre hubo danzas de los caballeros y gentileshombres en palacio, e momos e toros e juegos de cañas...", Crónica del Rey Juan II, ed. Cayetano Rossell, en Crónicas de los Reyes de Castilla, II, Madrid, BAE, 1987, p. 566 (Recuérdese que para esta misma ocasión el Marqués de Santillana, que había acudido en la comitiva, compuso la canción que comienza: «Quanto más vos mirarán, / muy exelente princesa, / tanto más vos loarán»). La Crónica de Juan $I I$ alude también a las fiestas de Vallodolid y Soria citadas en la nota anterior, si bien no habla de momos en la primera (p. 516), pero si en la segunda: «El Rey hizo gran fiesta a la Reyna; e en tanto que en Soria estuvo se hicieron grandes justas, donde salieron los caballeros ricamente abillados e después de aquéllos se hicieron danzas e momos" (p. 526); descripción que es ilustrativo comprar con la de la Refundición..., cit., p. 198: «Estas vistas duraron nueve días, en la qual la reyna fue muy servida del condestable e de los otros 
celebrados en 1461 en el palacio jienense del condestable don Miguel Lucas de Iranzo, que se hallan descritos en su citada Crónica. Fueron aquéllos momos de una mayor complejidad y artificio, y hasta con un cierto grado de ficción: en la sala de palacio aparecía una escuadra de gentiles hombres en figura de personas extranjeras, con falsos visajes y vestidos de nueva y galana manera, que fingían salir de un crudo cautiverio, del que les fue otorgada libertad condicionada para venir a honrar la fiesta del condestable y la condesa desposados; ponía cierre a todo la danza y el baile, que se prolongaron durante más de tres horas ${ }^{19}$. Todavía de mayor complejidad fueron los celebrados unos días después, según refiere también la Crónica: irrumpía en la misma sala «una infantería de pajes pequeños... vestidos de jubones de fino brocado»,

\begin{abstract}
los quales tomaron por invençión que era una gente de inota e luenga tierra, la qual venía destroçada e vençida de gente enemiga; e que no solamente les avía destroido sus personas e bienes, mas los tenplos de la fe suya, los quales bienes decian que entendian fallar en estos señores Condestable y condesa. E que viniendo çerca de aquella çibdad, en el paso de una desabitada selva, una muy fiera y fea serpienta los avia tragado, e que pidian subsidio para dende salir. A la puerta de una cámara que estava al otro cabo de la sala, enfrente do estava la señora condesa, asomó la cabeça de la dicha serpienta, muy grande, fecha de madera pintada; e por su artefiçio lançó por la boca uno a uno los dichos niños, echando grandes llamas de fuego. Y así mismo los pajes, como traian las faldas e mangas e capirotes llena de agua ardiente, salieron ardiendo, que pareçia que verdaderamente se quemavan en llamas. Fue cosa por çierto que mucho bien paresçió ${ }^{20}$.
\end{abstract}

Pero, aparte este tono celebrativo y encomiástico, como ha subrayado E. Asensio, el momo también podía derivar a asuntos amorosos y caballerescos, y «saltaba a la crónica mundana, a los galanteos de damas y galanes allí presentes $\rangle^{21}$, explotando entonces aquella asociación entre el torneo real y el amor cortesano, a través del simbolismo sugerente de las heridas, la victoria y la recompensa. En las citadas bodas del condestable Iranzo se representaron también momos de esta condición, sobre el motivo de la herida de amor:

cavalleros. E como el Rey avia llevado consigo muchos gentiles onbres, e la reyna de Aragón traia algunas fermosas damas, fiziéronse alli muchas justas e grandes fiestas de danças e momos)r.

${ }^{19}$ Hechos del Condestable..., ed. cit., p. 50.

${ }^{20}$ Ibid., pp. 50-51.

${ }^{21}$ E. Asensio, art. cit., p. 33. 
El jueves siguiente (...) se fizo un grande e muy frecuentado juego de cañas, do asaz cavalleros salieron feridos (...) $Y$ después de çenar, vinieron momos mancos, la meitad brocados de plata e la meitad dorados, con cortapisas, en las partes izquierdas sendas feridas, sonbreros de Bretaña, en ellos penas y veneras, y con sus bordones; e dançaron por grant pieça ${ }^{22}$.

El tema amoroso asociado con la justa y el ritual cortesano está asimismo presente en los momos que a su protagonista hace evocar Diego de San Pedro en el Tratado de amores de Arnalte y Lucenda (1491):

\begin{abstract}
Pues como ya la noche la priesa de los justadores en sosiego pusiese, cada uno por su parte se va a descansar, y la reina con las damas se fue a su posada. E como la hora del momear llegada fuese, y salidos los momos a la sala, cada uno con la dama que servía començó a dançar. Allí de mi dicha me quexé, y de mi soledad más me doli en verme de sus riquezas tan pobre (...). Pero con el pinzel de la vitoria en que estava matizava la pena por venir, y ansi unas marcas de alegria en el manto bordadas saqué; dezia la letra así:
\end{abstract}

Este triste más que hombre

que muere porque no muere,

bivirá cuando biviere

sin su nombre.

Cuando los momos ya acabados fuesen, dónde Lucenda estava asentada miré $(\ldots)^{23}$.

Los iuntos amoroso-caballerescos son igualmente tema esencial en los momos r iue conocemos de la corte portuguesa, que repiten una y otra vez los moti 'os de los cautivos libertados por el caballero tras vencer a los salvajes a los gigantes guardadores, o de las damas y galanes que piden remedio de sus amores al rey, etc. ${ }^{24}$.

$\mathrm{Si}$ bien es cierto que toda esta serie de espectáculos no eran propiamente teatro, si podría afirmarse que presagiaban un desarrollo teatral, que en-

${ }^{22}$ Hechos del Condestable..., ed. cit., p. 53.

${ }^{23}$ Diego de San Pedro, Tractado de amores de Arnalte y Lucenda, en Obras completas, I, ed. de Keith Whinnom, Madrid, Castalia, 1973, pp. 113-14. El pasaje fue ya recordado por A. Bonilla y San Martín, Las Bacantes, a del origen del teatro, Madrid, 1921, p. 81. Son escasos los testimonios sobre fiestas cortesanas que ofrece la novela sentimental, como puede verse en Michel García, "Les fêtes de cour dans le roman sentimental castillan", en La fête et l'écriture..., cit., pp. 33-49.

24 Vid. E. Asensio, art. cit. 
cerraban en potencia una pieza dramática. Había efectivamente en ellos una cierta acción y movimiento dramáticos, una minima sucesión de cuadros y escenas, unos actores que representaban distintos papeles y se servían de máscaras y visajes, $\mathrm{y}$, muchas veces, además del apoyo musical y rítmico, hasta un texto poético, por leve que fuese, que acompañaba a la mímica y al gesto. Para transformarlos en teatro, sólo faltaba la aparición de un autor dotado que supiese aprovechar las posibilidades dramáticas del momo. Es lo que, como ha mostrado E. Asensio, hizo en Portugal Gil Vicente, quien, en obras como Don Duardos y Amadis, acometió «la empresa de transmutar y metamorfosear en puro o casi puro drama los temas, personajes y espiritu del momo ${ }^{25}$. Y es también, sin duda, lo que hizo en Castilla, en la corte de los duques de Alba, Juan del Encina, quien igualmente supo aprovechar para su teatro el marco escénico del momo (la sala de palacio y el ambiente festivo), las máscaras y visajes (en este caso, la máscara pastoril) y los mismos asuntos encomiásticos y amorosos.

Relacionados también con este ambiente palaciego de que venimos tratando, hay otros textos literarios, transmitidos por los cancioneros poéticos de la época, cuya pura condición dramática puede ser discutible, pero que no se muestran ajenos a toda esta intensa actividad teatral. Son textos dialogados, en los que intervienen diversos interlocutores, con una apreciable acción y movimiento escénicos, y susceptibles, por tanto, de una representación, aunque no tengamos pruebas definitivas de que ésta se produjese. Por los temas en ellos tratados, podrían agruparse en dos categorías: unos textos que documentarían un teatro de asunto amoroso cortesano, y otros que supondrían un teatro de tema político y alegórico.

En el primer grupo habría que encuadrar el Diálogo del Viejo, el Amor y la Hermosa, anónima refundición libre del Diálogo del Amor y un viejo de Rodrigo Cota, pero más elaborado desde un punto de vista dramático y con mayor carga de elementos teatrales ${ }^{26}$. El asunto que pone en escena el Diálogo es, en efecto, el tópico del Amor y el Viejo, quienes se enzarzan en un largo y acalorado debate sobre las excelencias e inconvenientes de la pasión amorosa:

${ }^{25}$ Id. id., p. 34.

${ }^{26}$ Fue descubierto y publicado por Alfonso Miola, "Un testo drammatico spagnuolo del $\mathrm{x} V$ secolo», en In memoria di N. Caix e U. A. Canello. Miscellanea di filologia e linguistica, Florencia, 1886, pp. 175-89; Elisa Aragone lo ha publicado también como apéndice de su ed. de Rodrigo Cota, Diálogo entre el amor y un viejo. Florencia, Le Monnier, 1961, pp. 115-125; lo recoge asimismo R. E. Surtz en su Teatro..., cit., pp. 110-139. Recientemente ha sido estudiado en sus aspectos literarios por H. Salvador Martinez, "El Viejo, el Amor y la Hermosa y la aparición del tema del desengaño en el teatro castellano primitivo', $R C E H, 4(1980)$, pp. 311-27. 


\begin{tabular}{|c|c|}
\hline El AMOR & ¿Quién stá en casa? \\
\hline EL VIEJO & ¿Quién llam \\
\hline EL AMOR & ¡Abre! \\
\hline EL VIEJO & ¿Quién eres? \\
\hline $\begin{array}{l}\text { EL AMOR } \\
\text { EL VIEJO }\end{array}$ & ¿Qué quieres? \\
\hline EL AMOR & A tu vida y fama. \\
\hline EL VIEJO & $\begin{array}{l}\text { Va con Dios, que ya tu llama } \\
\text { no me causa más dolor. } \\
\text { ¿No sabes que ha muchos años } \\
\text { que de ti me hallo lexo? } \\
\text { Porque tus dulces engaños } \\
\text { me han fecho no menos daños } \\
\text { qu'el mundo de quien me quexo. }\end{array}$ \\
\hline El AMOR & $\begin{array}{l}\text { Desplázeme tu porfia, } \\
\text { no consiento tal olvido, } \\
\text { que no cabe en cortesia } \\
\text { desfacer la conpañia } \\
\text { después qu'es el pan comido (...). }\end{array}$ \\
\hline
\end{tabular}

En este caso, sin embargo, el Viejo termina siendo persuadido por el Amor y se apresta a cortejar a la Hermosa que aquél le presenta. A pesar de sus requiebros y galanteos, la Hermosa, cruel, lo rechaza, y queda el Viejo lamentando con desengaño su fracaso y ofreciéndose como escarmiento aleccionador a estos atrevidos amantes. El añadido de esta breve escena y peripecia, al igual que el personaje de la Hermosa, convierten el simple debate originario en una más compleja acción dramática, al tiempo que sirven de ilustración plástica al tema que motiva la obra: la imposibilidad del amor de viejo (tema, por lo demás, de amplia resonancia en la literatura de la época y para el que ésta ofrece también soluciones diferentes $)^{27}$. La sucesión de parlamentos largos y breves en un diálogo bastante fluido y dinámico, así como las continuas referencias a los gestos y actitudes de los personajes (el Amor pone la mano en el corazón del Viejo que de esa manera se le rinde, el Viejo se engalana para cortejar a la Hermosa y pide al Amor que le mire todo en derredor, el Viejo hace ademán de tocar a la Hermosa, etc.), las reiteradas llamadas a los espectadores, o el cierre final con un villancico como será característico en todo el teatro primitivo, hacen pensar decididamente en una ejecución escénica de la obra y resaltan su condición teatral.

Temáticamente próximas al Diálogo comentado se muestran las Coplas

27 Vid. H. Salvador, art. cit. Añádase también el testimonio de Santillana en sus Proverbios, vv. 749-52: «iO modesta vejedad, / que resfría / los viçios de mançebía / e moçedad!». 
de Puertocarrero, que nos ha transmitido el Cancionero General ${ }^{8}$. Son éstas también una curiosa escenificación de tópicos de la poesía cortesana de la época: el amante mártir y excesivo en su apasionamiento, la dama rigurosa y cruel, o la idea misma del servicio amoroso. Pero todo ello tratado con un sorprendente distanciamiento cómico y realista. Puertocarrero, que pasea por una calle penado de amores, es saludado desde una ventana por su dama, quien se halla en compañía de su amiga Jerez; a instancias de ésta, la dama invita al galán a subir junto a ellas; mientras sube la escala, Puertocarrero desconfia de las intenciones de la dama, pero al fin se decide y penetra en el aposento. El resto de la obra lo ocupa un extenso diálogo entre ambos personajes, en el que se vierten todos los tópicos del amor cortés por boca del protagonista, de los que se burla desdeñosamente la dama:

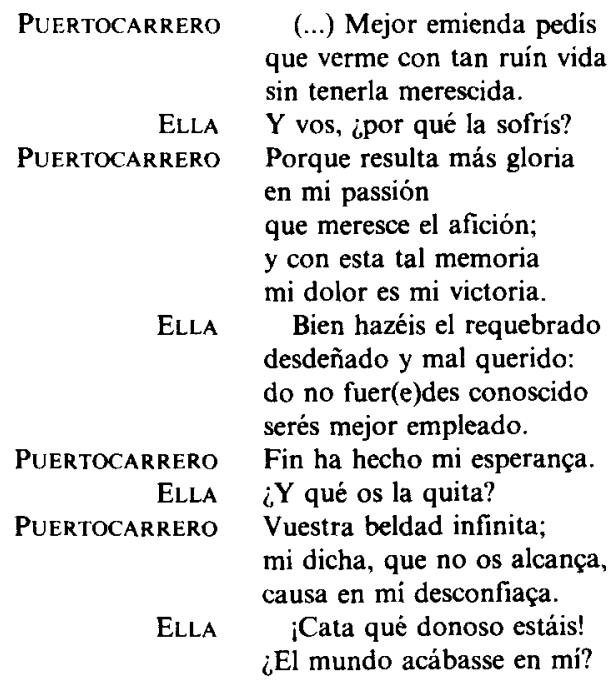

28 Las editó R. Foulché-Delbosc en su Cancionero castellano..., cit., II, pp. 674-82. Una versión modernizada del texto incluyó F. Lázaro Carreter en su Teatro medieval. Madrid, Castalia, $1965^{2}$, pp. 177-206. 


\begin{tabular}{|c|c|}
\hline PuertocarRero & $\begin{array}{l}\text { Para mí, señora, sí, } \\
\text { que del todo me acabáis. } \\
\text { Y con tan justa razón } \\
\text { pues yo os veo } \\
\text { cabo sois, porque el desseo } \\
\text { da comienço al afición } \\
\text { donde acaba el coraçón. } \\
\text { Acaba quien no comiença } \\
\text { a quexar sus desventuras. } \\
\text { Dexaos ya dessas locuras; } \\
\text { noramala avé vergüença (...) }\end{array}$ \\
\hline
\end{tabular}

Al cabo, para poner fin a esa interminable plática, Ella pregunta maliciosamente a Puertocarrero por su mujer, al tiempo que se hace servir la merienda, lo que no es sino una fina manera de despedir al molesto amante. Éste queda aún más ridiculizado ya que, puesto que no es admitido como servidor de amores, se conforma al menos con aprestarse a servir las viandas de la merienda a la dama, lo que resulta una cruel parodia del "servicio" amoroso. Como se ve, la obra, por su variedad de situaciones escénicas y de personajes, así como su diálogo muy vivo y animado, puede ser tenida como un claro experimento teatral. El tratamiento burlesco del discurso y los comportamientos amorosos (como también ocurre en La Celestina y en las comedias de Naharro) la inscriben en el mismo género de teatro cortesano que el comentado Diálogo del Viejo, el Amor y la Hermosa. Teatro que, como parece desprenderse de estas obras, tomaba como asunto central la desarticulación literaria, en clave realista y burlesca, del código amoroso cortesano, teñido todo de un cierto tono de desengañado pesimismo.

A un teatro de carácter político-alegórico pertenecería, en cambio, la Égloga de Francisco de Madrid, compuesta hacia mediados de 1495, por quien era seguramente secretario del Rey, y representada poco después en la corte quizá ante embajadores italianos. La obra trata de los sucesos de la invasión de Nápoles por Carlos VIII de Francia y la intervención de Fernando el Católico que acude a defenderla, todo ello bajo una ficción alegórica protagonizada por tres pastores, Evandro «que publica e introduce la Paz", Peligro que representa al joven y ambicioso Carlos, y Fortunado que encarna al pacificador Fernando. En su diseño artístico confluyen así en la pieza, como ha subrayado Alberto Blecua, tradiciones literarias muy diversas, desde la égloga virgiliana y la égloga humanística a la tradición alegórico-política y pastoril de las Coplas de Mingo Revulgo, y se produce una curiosa mixtura artística en virtud de la cual aparecen combinados en el tex to el estilo humilde, propio de los personajes pastoriles, y el arte mayor, dada la verdadera condición elevada de éstos en su proyección alegórica ${ }^{29}$.

${ }^{29}$ Alberto Blecua, «La Égloga de Francisco de Madrid en un nuevo manuscrito del siglo 
Menos atendida ha sido la Égloga sobre el molino de Vascalón, que también habría que incluir en este teatro de ficción alegórica y pastoril. Se trata de una pieza anónima muy breve - poco más de un centenar de versos-, incluida en el llamado Cancionero de Pero Guillén de Segovia, copia dieciochesca de una colección antigua que contiene composiciones de finales del siglo XV y principios del XVI. ${ }^{30}$ La Égloga pone en escena un breve diálogo entre el rústico Íñigo (Mingo) Sicio, que acude a maquilar al molino, y Juan, el nuevo molinero que pondrá fin al mal funcionamiento y abusos con que antes de su llegada se realizaba la molienda. La obra hace uso muy intenso de la lengua pastoril y bajo ese ropaje alegórico, al que seguramente da pie el simbolismo que la tradición había creado en torno al personaje del molinero $^{31}$, alude a un inconcreto acontecimiento político, social o religioso (¿la llegada de un nuevo prelado a una diócesis?) ${ }^{32}$, que denuncia una situación a la que pondrá orden y sosiego el nuevo molinero:

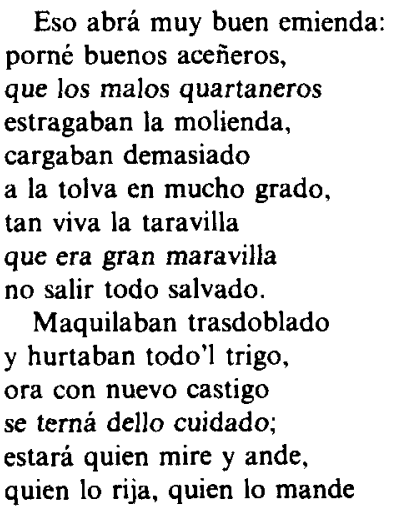

XV1», en Serta Philologica F. Lázaro Carreter, II, Madrid, Cátedra, 1983, pp. 39-66. Basándose en la copia moderna de Cañete, la había editado J. E. Gillet, «Égloga hecha por Francisco de Madrid, 1495?), $H R, 11$ (1943), 275-303; en versión modernizada la incluye F. Lázaro Carreter en su Teatro medieval, cit., pp. 155-76.

"De ahi la publicó J. E. Gillet, "The Égloga sobre el molino de Vascalón", PhQ, 5 (1926), pp. 87-89. A este teatro de fines del siglo xv la adscribió también A. Bonilla, Las Bacantes..., cit., p. 87, $\mathrm{n}$.

"Véase el documentado estudio de Agustín Redondo, "De molinos, molineros y molineras. Tradiciones folklóricas y litereatura en la España del Siglo de Oro", en Literatura y folklore: problemas de intertextualidad, Universidad de Groningen-Univesidad de Salamanca, Ediciones Universidad de Salamanca, 1983, pp. 101-115 (aunque no hay referencia a nuestra obra).

${ }_{32}$ La obra podría conectar así con el motivo del molino espiritual, que tiene amplio desarrollo en la literatura $y$ arte catalanes de finales del siglo $x v$ (vid. A. Redondo, art. cit., pp. (11-12). 
con derecho, con vivez, tal que no quite la vez al que quitó por el grande.

Volverál costal tan lleno que, después de maquilado, el menguado quede lleno y el lleno bien atestado; mas aqueste Vascalón es de una condición; qu'el remedio tiene caro si le non ponen reparo los maestros d'Aviñón.

Después de este repaso, necesariamente breve y sucinto, de las noticias y textos dramáticos que poseemos del siglo $\mathrm{xV}$ - fuera de los casos bien conocidos de Juan del Encina y Lucas Fernández-, conviene ahora, a modo de conclusión, hacer algunas consideraciones que tal vez permitan entender mejor este tipo de teatro y definir su condición y categoría literaria, bastante alejada de nuestra concepción moderna del hecho teatral.

En primer lugar, hay que tener en cuenta que nos hallamos ante unas obras que no poseen una realización textual propia y que tampoco era habitual recoger por escrito (ni las crónicas ni los documentos eclesiásticos, que, como hemos visto, abundan en noticias, sienten la necesidad de transcribir los textos). Las que nos han llegado lo han hecho mayoritariamente a través de la vía más común de transmisión literaria en la época: el cancionero poético. Tal ha sido, en efecto, la transmisión de las piezas de Gómez Manrique, en los manuscritos de su propio cancionero individual $1^{33}$; la del Diálogo del viejo, el Amor y la hermosa, en un cancionero de la Biblioteca Nacional de Nápoles que contiene poesías en italiano y en castellano ${ }^{34}$; la de las Coplas de Puertocarrero, en el Cancionero de Rennert, de hacia 1500, y en el Cancionero General de Hernando del Castillo ${ }^{35}$; la de la Égloga de

${ }^{33}$ Las dos copias que de éste se han conservado, el ms. 1250 de la Biblioteca de Palacio y el ms. 7817 de la Biblioteca Nacional de Madrid, recogen en sus folios la Representación del nacimiento, los momos al nacimiento de un sobrino suyo y los momos al príncipe don Alfonso. En cambio, las Coplas fechas para la Semana Santa nos han llegado únicamente en la copia del Cancionero de Pero Guillén de Segovia.

${ }^{34}$ Puede verse su descripción en Brian Dutton y colaboradores, Catálogo-índice de la Poesía Cancioneril del siglo XV, Madison, 1982, p. 93.

${ }^{35}$ Cancionero General recopilado por Hernando del Castillo (Valencia, 1511), ed. facsímil de A. Rodríguez-Moñino, Madrid, 1958, fols. 160v-163v; Hugo A. Rennert, "Der spanische Cancionero des British Museum (Mss. Add. 10431)", RF, 10 (1899), pp. 1-176. 
Francisco de Madrid, en el Cancionero de Palacio ${ }^{36}$; o la Égloga del molino de Vascalón, en el Cancionero de Pero Guillén de Segovia ${ }^{37}$. Incluso el Auto de la huida a Egipto aparece recogido en un volumen facticio que contiene varios poemas manuscritos y dos obras impresas, todas de asunto religioso ${ }^{38}$. Sólo el Auto de Alonso del Campo, como dijimos, nos ha llegado por una vía distinta de transmisión, aunque también algo indefinida y fortuita: unos folios sobrantes en unos de los libros de gastos de la catedral de Toledo ${ }^{39}$.

Esto quiere decir que no existe todavía en el siglo xv una escritura específica del género teatro y que éste adopta el modelo convencional y dominante de la poesía de cancioneros, cuando no la copia ocasional y descuidada. Como ha dicho F. López Estrada refiriéndose a Gómez Manrique, "el autor de la Representación recoge esta experiencia de la escritura de los códices poéticos y la adapta para establecer las peculiaridades propias de la obra teatral (...). Se trata, pues, del uso del convencionalismo de la escritura de la lírica cancioneril aplicado a una finalidad dramática; o sea, la constitución de un nuevo convencionalismo que recoge sólo parte de la complejidad de la obra dramática» ${ }^{40}$. Debido a ello los textos dramáticos se nos aparecen en una forma de presentación muy similar a la de los puros textos poéticos, con los que tienden externamente a confundirse. Como éstos, irán encabezados por una rúbrica que nos ofrece escuetas noticias de las circunstancias de su composición («La Representación del Nascimiento de Nuestro Señor, a instancia de doña María Manrique, vicaria en el monesterio de Calabaçanos, hermana suya. De Gómez Manrique»), aunque alguna vez en ese espacio convencional se mezclan estas noticias con un conato de resumen argumental y de acotación escénica («Coplas que hizo Puerto Carrero porque passando un día por una calle donde su dama estava con una compañera suya, y tanbién tercera de él, que se llamava Xerez, las quales él no avía visto, fue llamado por su señora, y començaron a hablar los dos; y algunas vezes ella burlando de él y desfraçándole...» ${ }^{41}$. De igual

${ }^{36}$ Cancionero de poesias varias. Manuscrito n. 617 de la Biblioteca Real de Madrid, ed. de José J. Labrador, C. Ángel Zorita y Ralph A. DiFranco, Madrid, El Crotalón, 1986, núm. 94.

$"$ Ocupa alli los fols. 199r-202r, entre composiciones del s. xv y otras del xvi; sobre las particularidades de este cancionero, John G. Cummins, «Pero Guillén de Segovia y el Ms. 4114», HR, 41 (1973), pp. 6-32.

${ }^{38}$ Procede de Santa María de la Bretonera y se conserva en la Biblioteca Nacional de Madrid, ms. R-31133'; los diez primeros folios contienen diversos poemas religiosos manuscritos, entre los que se encuentra nuestro auto $(2 \mathrm{r}-5 \mathrm{v}$, sin otro encabezamiento que: «El ángel a Josepe»); el resto del volumen lo ocupan dos impresos: la Historia de San Jerónimo, Zaragoza, Coci, 1510 (1 1r-88v), y el Retablo de la vida de Crista de Juan de Padilla, Sevilla, Cronberger, $1510(89 \mathrm{r}-146 \mathrm{v})$.

${ }_{39}$ Vid. Carmen Torroja y Maria Rjvas, Teatro en Toledo..., cit., pp. 77-80.

* F. López Estrada, "La Representación...", art. cit., p. 28.

${ }^{4}$ Es la rúbrica que ofrece el Canc. General; la del Cancionero de Rennert es bastante 
modo, el título tiende a acomodarse al de las composiciones poéticas en las rúbricas («coplas», "[diálogo]. Interlocutores senex et amor mulierque pulcra forma"), o se introduce al más ambiguo, culto y tardío de "égloga». También, por las mismas razones, la transcripción viene a limitarse a lo que llamariamos con $\mathbf{R}$. Ingarden el "texto principal», reduciéndose al minimo el «texto secundario», esto es, las acotaciones escénicas, así como las marcas de la alternancia de personajes en el diálogo ${ }^{42}$. Con todo ello se comprende que resulte problemática la plena caracterización de tales textos como teatro y prácticamente imposible la reconstrucción de su puesta en escena. Si se nos han conservado, ha sido más como textos poéticos que porque se reconocieran y valoraran como teatro. Y siempre nos quedará la duda de cuántas composiciones poéticas de los cancioneros tuvieron un origen dramático o sirvieron en una representación. Sabemos que eso ocurrió, por ejemplo, con la Pasión trovada de Diego de San Pedro, pero pudo ocurrir con otros textos, como el episodio pastoril que incorpora Fray Íñigo de Mendoza a su Vita Christi, e incluso muchos poemas encomiásticos («por estrenas») y amorosos (canciones, letras, invenciones) pudieron haber nacido o ser empleados como ilustraciones de momos y dramatizaciones cortesanas.

Una segunda consideración es que nos hallamos ante un teatro que oscila descompensadamente entre la palabra y el gesto. Es cierto, como se ha dicho, que ambos elementos van siempre asociados al espectáculo teatral que se balancea entre uno y otro, pero que en su compensación y equilibrio reside el drama auténtico. Nuestro teatro, en cambio, es casi puro gesto, como ocurre en el momo, o es casi sola palabra, como en los autos, diálogos y églogas. Pero lo que falta siempre es acción, trama argumental. Se trata, en cambio, de un teatro muy estático, que se resuelve en gesto y alarde visual, cuando no en largos parlamentos didácticos y piadosos o en densas confrontaciones dialécticas en la tradición de los viejos debates medievales.

Por último, no podríamos considerar tampoco a la mayoría de estas obras y espectáculos como puras creaciones dramáticas, por cuanto tampoco parece que persigan el puro goce estético y literario. En ese sentido, como bien ha advertido Charlotte Stern, están más cerca del acto ritual, que tiene una finalidad más inmediatamente práctica y en el que toma parte

diferente: «Puerto Carrero. Este caballero servía por amores una señora, solo por ser favoreçido della y no por más, y creçiéndole la pasión, pedía remedio. Ella, viendo que su fin se endereçaba a destruir su onrra, comunicólo con otra señora, su amiga; y un día, entrando este caballero en un patio, estando ella en unos corredores, comenzóle ella a dezir y él a responder, a la terçera a entrebenir entre ellos, y ansí comiença la obra donde dize ellan. Como se advierte, la rúbrica es aquí más novelesca y poética - también bastante desviada del verdadero sentido de la obra-, y mucho menos «teatral».

${ }^{42}$ Cfr. Roman Ingarden, "Les fonctions du langage au théatre», trad. francesa, Poétique. 8 (1971), 531-38. 
toda la colectividad ${ }^{43}$. En nuestras obras, en efecto, la representación brota de la propia fiesta y celebración sin solución de continuidad: después de la misa o de los oficios, en el caso de los autos; o tras el torneo y la cena, en los espectáculos cortesanos. Se produce igualmente en el mismo recinto de la fiesta (el templo, la capilla del convento o la sala de palacio), y es ejecutada por los propios celebrantes y participantes (los clérigos, las religiosas - los personajes de la corte), de manera que, aunque sólo sean unos cuantos quienes la interpreten, todos los espectadores se sienten identificados emocionalmene con los actores y se tienen por partícipes de ella. En las iglesias, la representación tendrá fundamentalmente una finalidad celebrativa y devota: la evocación piadosa de los misterios de la religión. En la corte, apuntará, sobre todo, a la exaltación de la sociedad cortesana y feudal, subrayando las relaciones de dependencia y la armonía social del grupo, y alabando las virtudes y empresas del señor.

Para concluir, diríamos que estos textos y espectáculos del siglo Xv constituyen un tipo de teatro muy especial, dificil de delimitar literariamente, que oscila entre la palabra y el gesto, entre el rito y la creación artística, y que, en consecuencia, está lejos de la idea moderna de teatro. Ello no autoriza, sin embargo, a negar su categoría y condición dramática, sino que exige que sea contemplado y estudiado con ojos diferentes a aquellos con que estamos acostumbrados a ver el fenómeno teatra ${ }^{44}$.

" Charlotte Stern, "Fray f́ñgo de Mendoza and Medieval Dramatic Ritual», $H R, 33$ (1965), 197-245, especialmente pp. 211-15; Id., "The Early Spanish Drama: From Medieval Ritual to Renaissance Art", Renaissance Drama, New Series, 6 (1973), pp-177-201.

${ }_{44}$ El presente artículo es reelaboración de una conferencia leída, en diciembre de 1987, en el Centro Asociado de la UNED en Málaga, y que se edita también en el colectivo Sobre poesía y teatro. Cinco estudios de literatura española, publicado por el propio Centro. 